\title{
Digital Engineering Education Applications
}

\author{
CALIN CIUFUDEAN and CORNELIU BUZDUGA \\ Faculty of Electrical Engineering and Computers Science \\ University Stefan cel Mare of Suceava \\ 13 University \\ ROMANIA \\ calin@eed.usv.ro, cbuzduga@eed.usv.ro
}

\begin{abstract}
In this paper we introduce a new concept that defines the global economy and modern style of life: the digital engineering education. A digital engineering educational (DEE) system consists of a planned, specialized teaching experience, organized by an IT specialized institution. The educational process suffers deep changes under the imperative of technological development, e-learning is just one example. For example digital environment extends its application area, such as commerce, communications, medicine, engineering, social media, s.a. as it is used to experiment new connections between different systems represented by artificial social systems. The pedagogic methods capable to insure the success of the digital engineering systems represent a major challenge for specialists, therefore we propose a suggestive example in order to link theory with practice.
\end{abstract}

Key-Words: - digital engineering, e-learning, e-trade, computer network, internet, social and economic systems.

Received: August 12, 2019. Revised: January 3, 2020. Accepted: January 18, 2020.

Published: January 29, 2020.

\section{Introduction}

A digital engineering educational (DEE) system consists of a planned, specialized teaching experience, organized by an IT specialized environment or institution. The DEE process supposes that the educational support is permanently available and it is delivered immediately to the students. The students assimilate the material in their own rhythm, without any constraints of presence of courses. The support for courses is an electronic one, such as: CD (also possible by e-mail) and Internet [1-4]. The task of the education based on a new information technology is to substitute a part of the present educational structures and not to encourage a competition with the old educational system.

The inherent changes in culture and civilization will probably confirm the superiority of the elearning system. First of all we notice the digital conversion of the world cultural technological inheritance that results in their large availability. The actual structure of communication is going to be changed by the computer networks that connect digital libraries to schools and homes, and this will change the social basis of the educational and cultural teaching processes. The picture below will substitute the old self sufficient and weighty systems. The free access to culture will be provided by the new educational system which will suffer a deep, one-way change, according to the new

technical environment. Secondly, the simulation of interactions between facts and ideas will extend the artificial intelligence acquisition to common senses thus, modifying the new cultural support. The epistemological development acquires interesting aspects. The thinking has a close relation with the language, and the mathematical formal representation is considered as an extension of various linguistically forms. Obviously, the digital environment extends the area, as it is used to experiment new connections between different systems represented by artificial social systems. Third, the digital technologies enlarge the personal potential. For example, the text editors warn about the wrong spelling, the tabular programs allow anyone to calculate fast and correct. The remainder of the paper is organized as follows. We provide a description e-learning support for DEE in Section 2. Dee applications in commercial transactions are investigated in Section 3. Section 4 illustrates a pedagogic example of DEE, and concluding remarks are summarized in Section 5 of the paper.

\section{E-learning Support of DEE}

Digital libraries, multimedia and Internet have considerably changed the view over the educational process. The technological development, the new teaching theories and the sharing of educational 
responsibility determine new characteristics of educational systems, such as:

- The flexibility of the parts played in the system;

- Curriculum directed to the specific student's needs;

- Shared resources;

- Asynchronous courses.

A virtual educational institution is an institution that provides the courses directly through the electronic communication technologies. It can also be defined as an organization that facilitates teaching and learning without direct implication as an educational program provider. These virtual institutions can be both public and private, at each educational level (elementary, secondary and academic) as well as non-formal permanent educational process (postgraduate). Virtual institutions emerge from four different sources:

- Institutions involved in the long distance open teaching system;

- Traditional schools and universities not involved in the long distance open programs. They start to implement the new informational technologies to increase quality and availability, this reducing the costs and increasing the incomes by attracting new social categories of students;

- Large corporation which develops internal virtual improving programs;

- Motivated individuals who use the electronic technologies to provide learning opportunities for anyone.

We must notice that an e-learning system is a business opportunity for the institutions mentioned above. As shown in [1], [2] feasibility studies for elearning systems introduce new parameters that allow the comparison between the old and the new educational systems; such as:

a) The scale - the number of the participants involved in a learning activity in a fixed period of time. It also includes the distance between the participants that can be covered by the system;

b) The perception - the technical quality of the teaching support;

c) The symmetry - the extension of focusing the attention on every student, according to the number of students;

d) The interactivity - the shortest period of time in which one can get an answer in an interaction;

e) The means - the tools available for the students in order to learn and communicate;

f) The student's control - the degree of communication between different students; and between students and professors;

g) The integration capability - the possibility to provide information in various ways and from various sources;

h) The costs - the expenses made by students;

i) The time - the necessary period of time for a student to achieve a fixed goal;

j) The flexibility - the easiness to modify the curriculum during the DEE process.

\section{DEE Application on Commercial Transactions}

The parameters mentioned in the above paragraph status a 1 ot of statistical studies [3-6]. These studies show that, despite the inherent inertness characteristic to major changes, the elearning technologies become more and more important all over the world. This creates the premise to the DEE teaching process development.

In the DEE process development, major contributions have the parents and students, which consider that the access to the long distance programs represents an educational right. The DEE also induces a simulative and easy environment for continuous improvement during the active period of life. The question is if a potential employer accepts a graduation diploma from a long distance program. It is difficult to answer to this question. Statistically, the common perception of the long distance programs in USA [7-12] shows the following:

- Only $30 \%$ of the professionals working in human resources departments have interviewed online graduates;

- $77 \%$ of them consider that an online diploma from a traditional school (university) is better than one obtained from a virtual institution (Jones International);

- $\quad 26 \%$ of them consider an online diploma as good as a conventional one;

- $\quad 61 \%$ of them sustains that an online diploma is acceptable, although not as good as a conventional one.

Most of the statistics show the value of the elearning systems. They underline the students' satisfaction as consumer of the new technologies in order to maintain them in the online marketing processes.

Using the electronic devices and know-how in commerce we have the phenomena of e-trade. In a very tide connection with e-trade there are the 
electronics businesses, which involve also the commercial transactions and the collaboration between partnerships, and even directing companies on-line. Performing classic commercial transactions we distinguee the following stages [13]: (a) The marketing research; (b) Signing the contract; (c) Delivering the product; (d) The payment. These four components of the e-trade, or e-commerce, are represented schematically in the following picture:

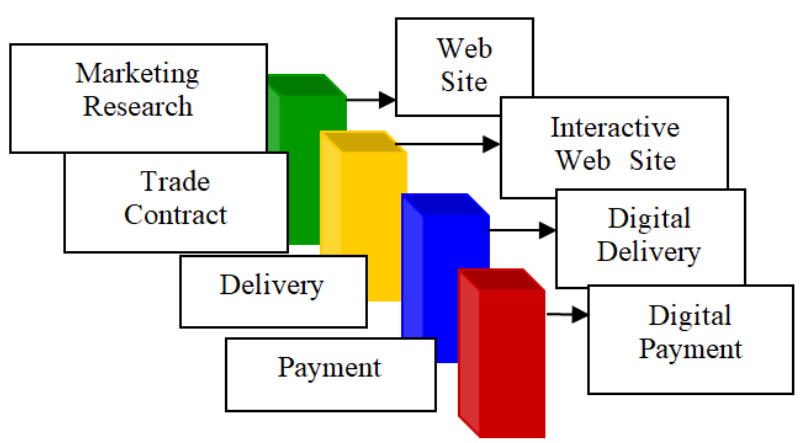

Fig. 1: The E-trade Components

\subsection{E-trade Models}

The most widely-spread models of e-trade are as follows [14]:

- Business to business (B2B);

- Business to consumer (B2C).

- Business to government (B2G).

\subsubsection{B2B Transactions}

B2B is an E-Trade model between companies and other organizations. The B2B field is a promising investment mainly because numerous profitable organizations are interested in it. Recent studies show that there are $1.1 \mathrm{~b}$ illion users that access the Internet from their workplace (including school and universities) and over 42000 registered higher-level fields.

\subsubsection{B2C Transactions}

This type of transactions is between individual buyers and large company suppliers. In this case the human factor is much more important, with interaction being the basic characteristic in the buying decision.

\subsubsection{B2G Transactions}

Governments use E-Trade links to enhance the efficiency of operations, and to improve the quality of the service offered to their clients. A field of interest for Governments in business is the largescale utilization of the Internet and WAN nets to disseminate information, opportunities, and the marks given by goods suppliers. The implication of governments in the E-Trade has a benefice effect for local economies, mainly because the main buyer is the public sector; therefore the government's involvement in the e-markets consist not only in lows support but also as an active participant in ETrade, and as a consultant for new e-companies.

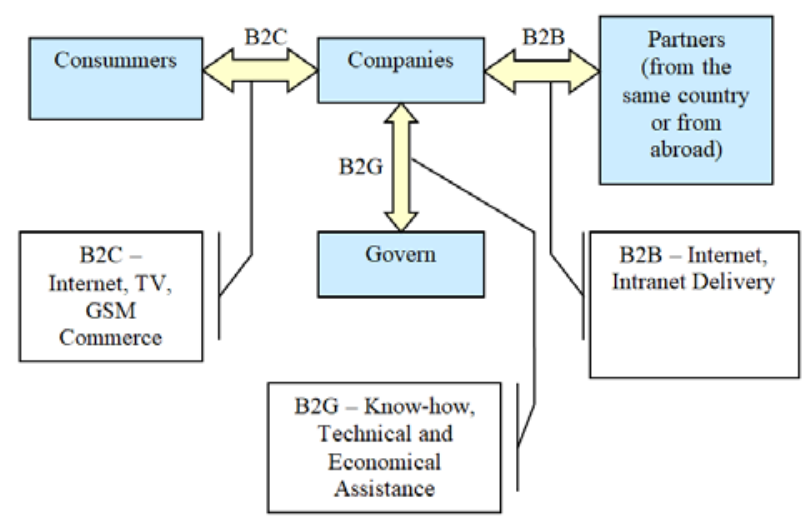

Fig. 2: The E-trade Stages

We also mention some other types of e-trades:

- C2B (consumer-to-business): This ecommerce concerns the physical persons (here referred as consumers) that perform trade, including the related activities, through the Internet.

- C2C (consumer-to-consumer): This ecommerce concerns the direct relations between consumers, respectively the trade performed straight from consumer to consumer.

- G2B (government-to-business): This ecommerce concerns the trade between official institutions and companies or physical persons.

- G2C (government-to-consumer): This ecommerce concerns the relations between public institutions and the citizens, for example the tax collecting.

\section{An Example of DEE System for E- trade}

In the previous sections of our paper we have discussed about two main characteristics of the modern life: e-learning and e-trade, as representative components of the concept that we introduce here: common applications of DEE, respectively the set of IT devices, tools and services that transform our behavior, environment, and ultimately our life.

In order to exemplify the advantages of this new concept we have designed, built and experimented, in our laboratory of Discrete Event Systems, an intelligent refrigerator called Smarti. Smarti represents a system capable to perform the necessary operations for an efficient e-trade and, 
even more, to administrate the products that are store in it.

More precisely, Smarti orders, pays and stores in a refrigerator until the goods are consumed, and then order again by e-mail and SMS another food products that restore the food supply.

Our system identifies itself the food necessary supply by counting the food that gets in and out the refrigerator, transmits these data to a computer that administrates the process, pays the shopping on-line and communicates with the merchants, and also memorize, brows the net in order to find the best offer for the new entries, respectively the products that the consumer wants to achieve.

Smarty has two main components: the hardware system, and respectively the software system. The hardware system uses RFID and pattern recognition components in order to identify the food supply in the refrigerator, and the software system uses the Java support for Internet communication and some dedicated algorithms that we created for local data base administration related to the data base of the merchants, so that every food product that is achieved by the best offer in the e-market.

A block diagram of the Smarty system is represented in the figure 3 .

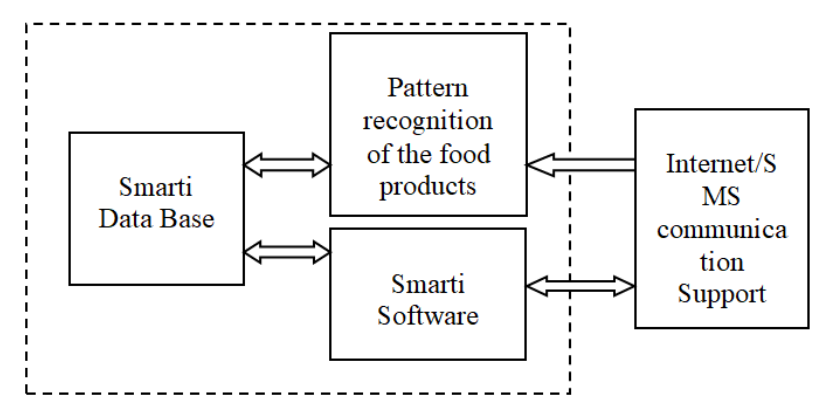

Fig. 3: Smarti Architecture

\section{Conclusion}

Obviously, the common perception about online courses, respectively to the digital engineering process is tributary to many prepossessions. The mean of the specialist involved in the e-learning systems is to improve the image of this new educational process. This requires the up-gradation of professional standards in online teaching systems. It must be turn to account the advantages offered by the new technologies, such as: eliminating the space, time, social, racial barriers as well as nonimposing a specific rhythm for learning.

The pedagogic methods capable to insure the success of the digital engineering systems represent a major challenge for the specialists involved in these new educational systems, including for those involved in the IT economical processes, such as the e-commerce. We co nsider that a $\mathrm{v}$ ery applicative way to achieve these approaches in the e-learning and e-commerce students training processes is the practice approach, and therefore we shortly have described an intelligent system designed built and experimented in our laboratory for performing etrade. We n otice that aspects of e-communities, emanagement, e-governance, tele-working should be included in the concept we propose here, respectively e-being, in order to have a whole picture with all the aspects that involve in our life. Our future work will focus on this subject.

\section{References:}

[1] H., Albach, H., Meffert, A., Pinkwart, R., Reichwald, Management of Permanent Change, Springer Fachmedien Wiesbaden, Wiesbaden, 2015.

[2] J.M., Leimeister, Einführung in die Wirtschaftsinformatik. Springer, Berlin, Heidelberg, 2015.

[3] G., Remane, B., Hildebrandt, A., Hanelt, L. M., Kolbe, Discovering New Digital Business Model Types - A Study of Technology Startups from the Mobility Sector. Pacific Asia Conference on Information Systems, PACIS 2016.

[4] G., Remane, A., Hanelt, R. C., Nickerson, L. M., Kolbe, Discovering Digital Business Models in Traditional Industries. Journal of Business Strategy Vol. 38, 2017, pp. 41-51.

[5] J. J., Zhang, Y., Lichtenstein, J., Gander, Designing Scalable Digital Business Models, Advances in Strategic Management, Vol. 33, 2015, pp. 241-277.

[6] R., Bärenfänger, B., Otto, Proposing a Capability Perspective on Digital Business Models, IEEE 17th Conference on Business Informatics, vol. 1, 2015, pp. 17-25.

[7] J., Gustafsson, Single Case Studies vs. Multiple Case Studies. A Comparative Study, 2017.

[8] R. K., Yin, Case Study Research. Design and Methods. SAGE Publications, 2009.

[9] R., Johansson, On Case Study Methodology. Open House International, Vol. 32, 2007, pp. 48-54.

[10] F., Höning, Methodenkern des Business Engineering: Metamodell, Vorgehensmodell, Techniken, Ergebnisdokumente und Rollen, 2009.

[11] A., Braune, C., Landau, FinTech - Digitale Geschäftsmodelltransformation im Bankensektor, Digitale Transformation von 
Geschäftsmodellen: Grundlagen, Instrumente und Best Practices, Springer Fachmedien Wiesbaden, Wiesbaden, 2017, pp. 495-519.

[12] H., Albach, H., Meffert, A., Pinkwart, R., Reichwald, Management of Permanent Change. Springer Fachmedien Wiesbaden, Wiesbaden, 2015.

[13] A., Osterwalder, Y., Pigneur, Designing Business Models and Similar Strategic Objects, The Contribution of IS. Journal of the Association of Information Systems, Vol. 14, 2013, pp. 237-244.

[14] M. M., Al-Debei, R., El-Haddadeh, D., Avison, Defining the Business Model in the New World of Digital Business. 14th Americas Conference on Information Systems, Vol. 3, 2008. 